\title{
Arthroscopic excision of intraarticular subperiosteal osteoid osteoma of talar neck: A case report
}

\author{
Bülent Özdemir (D), Sercan Akpınar (1) \\ Department of Orthopedics and Traumatology, Medline Hospital, Adana, Turkey
}

Osteoid osteoma (OO) has been seen in the metaphysis and diaphysis of the long bones, and almost half of it in the long bones of the lower extremities. However, it can be observed intraarticularly. Osteoid osteoma is clinically, radiologically, and pathologically a welldefined benign osteoblastic bone tumor. ${ }^{[1]}$ The talus is involved in 2 to $10 \%$ of $\mathrm{OO}$ cases, and $97 \%$ of talar $\mathrm{OO}$ cases are located in the talar neck. ${ }^{[2]}$ The most frequent symptom is significant nocturnal pain which is alleviated by the use of nonsteroidal anti-inflammatory drugs (NSAIDs) or acetylsalicylic acid. ${ }^{1}$ Intraarticular lesions may be misdiagnosed because clinical symptoms are not specific and may include findings such as effusion, heat increase, tenderness, stiffness, muscle atrophy, and joint degeneration. ${ }^{[3]}$ Osteoid osteoma in the talar neck could be misdiagnosed as other conditions accompanied by chronic ankle pain including ankle impingement syndrome, stress fracture, osteonecrosis, osteomyelitis, chronic ankle sprain, and inflammatory arthropathy. ${ }^{[4]}$ The average lag time between symptom onset and a diagnosis of

Received: March 20, 2020

Accepted: April 09, 2020

Published online: September 11, 2020

Correspondence: Bülent Özdemir, MD. Güzelyalı Mah, 81190 Sok, Safir Deluxe Sitesi, A Blok, D: 34, 01170 Çukurova, Adana.

E-mail: bulent0116@hotmail.com

Doi: 10.5606/ehc.2020.71830

Citation: Özdemir B, Akpınar S. Arthroscopic excision of intraarticular subperiosteal osteoid osteoma of talar neck: A case report. Jt Dis Relat Surg 2020;31(3):639-643.

(2020 All right reserved by the Turkish Joint Diseases Foundation

This is an open access article under the terms of the Creative Commons Attribution-NonCommercial License, which permits use, distribution and reproduction in any medium, provided the original work is properly cited and is not used for commercial purposes (http://creativecommons.org/licenses/by-nc/4.0/).

\section{ABSTRACT}

Osteoid osteoma (OO) is a benign, small, and painful tumor typically seen in the subcortical shaft and metaphysis of the long bones of the lower limb. The occurrence of this type of tumor on the talar neck is rare and may cause limitation of range of motion of the ankle joint. In this article, a 17-year-old male patient had ankle pain and limitation of joint motion accompanied by synovitis. The $\mathrm{OO}$ in the intraarticular subperiosteal talar neck was successfully excised arthroscopically and the nidus was completely removed. The diagnosis was confirmed histopathologically in the postoperative period. In this case, we achieved a successful result with surgical treatment of benign bone tumor in the talus with intraarticular excision of the lesion arthroscopically.

Keywords: Arthroscopic excision, osteoid osteoma, talar neck.

OO in the talus is reportedly two to three years. ${ }^{[5,6]}$ The open technique is the method traditionally used to remove the nidus. Arthroscopy is technically difficult but has the advantage of being less invasive than arthrotomy; however, the risk of recurrence due to inadequate excision under a limited surgical field of view into the nidus via a small window of the cortex is the greatest concern. ${ }^{[7]}$

The rarer incidences of an intraarticular OO brings with it non-specific clinical manifestations which cause both diagnostic and therapeutic challenges. ${ }^{[6]}$

Minimally invasive ankle arthroscopy may be a superior decision in surgical management. This case report of a patient with an $\mathrm{OO}$ of the ankle joint is aimed to emphasize the role of arthroscopy while also providing a reference for reviewing and discussing current approaches in arthroscopic management. ${ }^{[8]}$

\section{CASE REPORT}

A 17-year-old, right-hand-dominant male patient presented with a two-year history of localized and persistent pain in the left ankle joint. There was a history of several traumas. On physical examination 

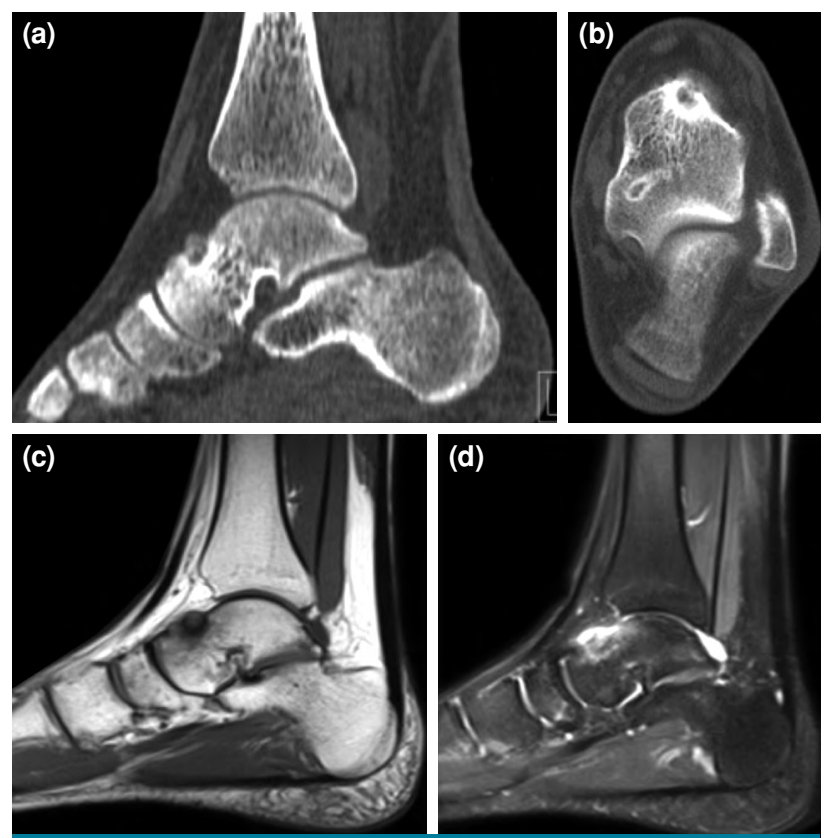

FIGURE 1. (a) Sagittal and (b) axial computed tomography images of left ankle showing central calcification within a radiolucent lesion of talar neck. (c) T1- and (d) T2-weighted sagittal magnetic resonance imaging showing a bone lesion in talar neck with surrounding bone marrow edema and synovitis in front of bone lesion.

of the ankle, there were no obvious abnormalities or swelling. The joint was tender with direct pressure but no erythema or warmth was noted. The range of motion of the ankle was limited and pain was reported at the limits of daily activities. The neurovascular examination was normal. His laboratory tests and plain radiography were normal. Working diagnosis after the initial assessment was tenosynovitis involving the left ankle. Nonsteroidal anti-inflammatory drugs were prescribed for six months with moderate improvement of symptoms but there was an element of nocturnal pain reported. Computed tomography (CT) scans demonstrated a focal nidus at the lateral distal part of the talar neck (Figure 1a, b). The findings were consistent with an intraarticular OO. Magnetic resonance imaging (MRI) views showed reactive bone edema in the talar head and neck areas, supportive of the diagnosis of $\mathrm{OO}$ (Figure 1c, d). A written informed consent was obtained from the legal guardian of the patient.

Surgery was performed under spinal anesthesia. The patient was placed in a supine position for arthroscopy. A tourniquet was placed around the proximal thigh and inflated to $300 \mathrm{mmHg}$ at the beginning of surgery. Standard anterolateral and anteromedial ankle arthroscopy portals were established and the anterior ankle compartment was viewed through a 30-degree arthroscope. The anterior tibia rim and talar dome were visualized, as well as the soft tissue covering the talar neck. The lesion appeared as an elevated hyperemic bony protuberance with adjacent synovitis (Figure 2). The nidus of the $\mathrm{OO}$ and circumferential sclerotic bone was curetted (Figure 3). The excision material was sent for pathological examination. Reactive hyperemic bony columns were completely cleared using a motorized burr. Histopathology confirmed the diagnosis of an OO.

There were no postoperative complications. Weight bearing was allowed as tolerated with the use of crutches and unrestricted range of motion. The patient reported pain reduction in the first postoperative week. Normal activities of daily living were resumed on the two- to four-week follow-up.
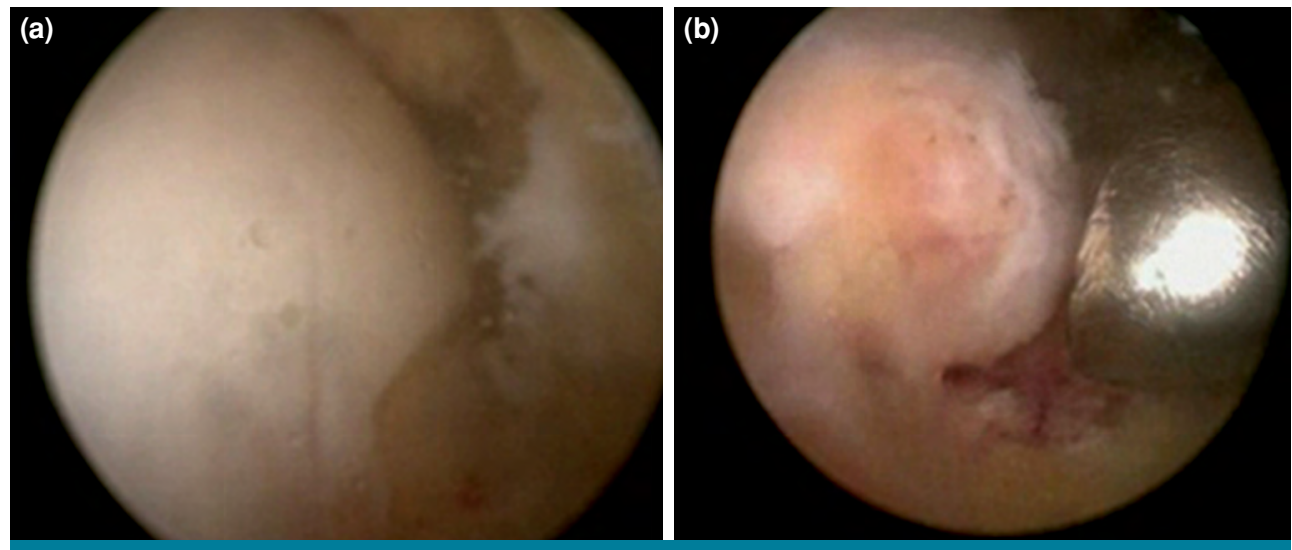

FIGURE 2. (a) Arthroscopy of left ankle joint. Hyperplasia with hyperemia of joint synovium was noted. (b) After synovectomy, a red subperiosteal lesion was seen through thinned cortex of talar neck. 

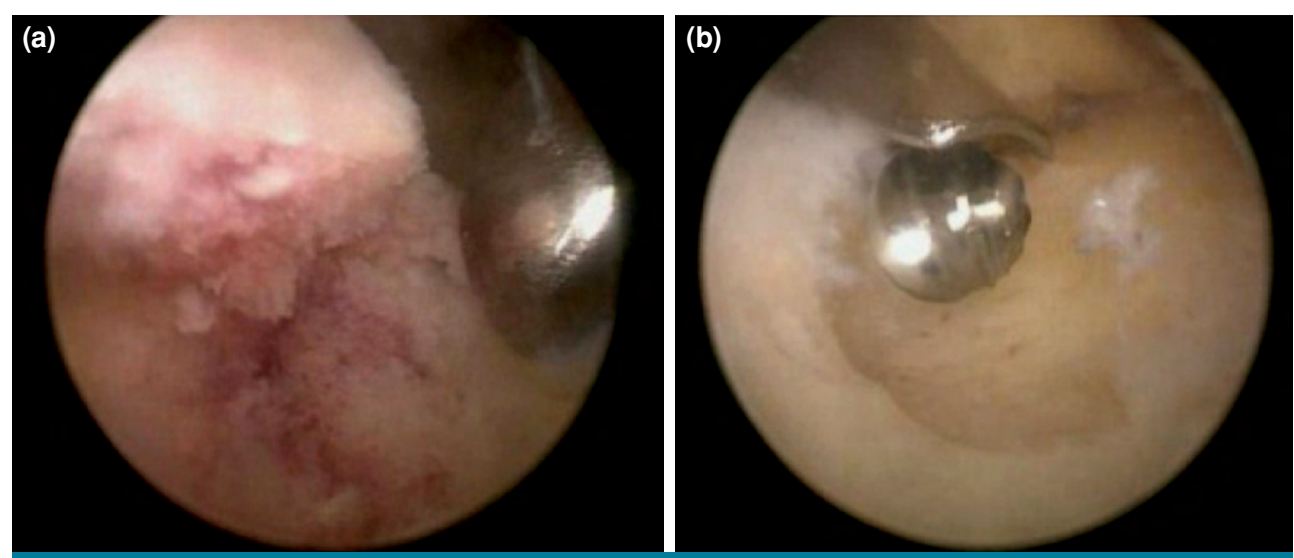

FIGURE 3. (a) After curettage of subperiosteal lesion, a red subperiosteal lesion was seen through reactive hyperemic bony of talar neck. (b) Reactive hyperemic bony columns were completely cleared using a motorized burr.
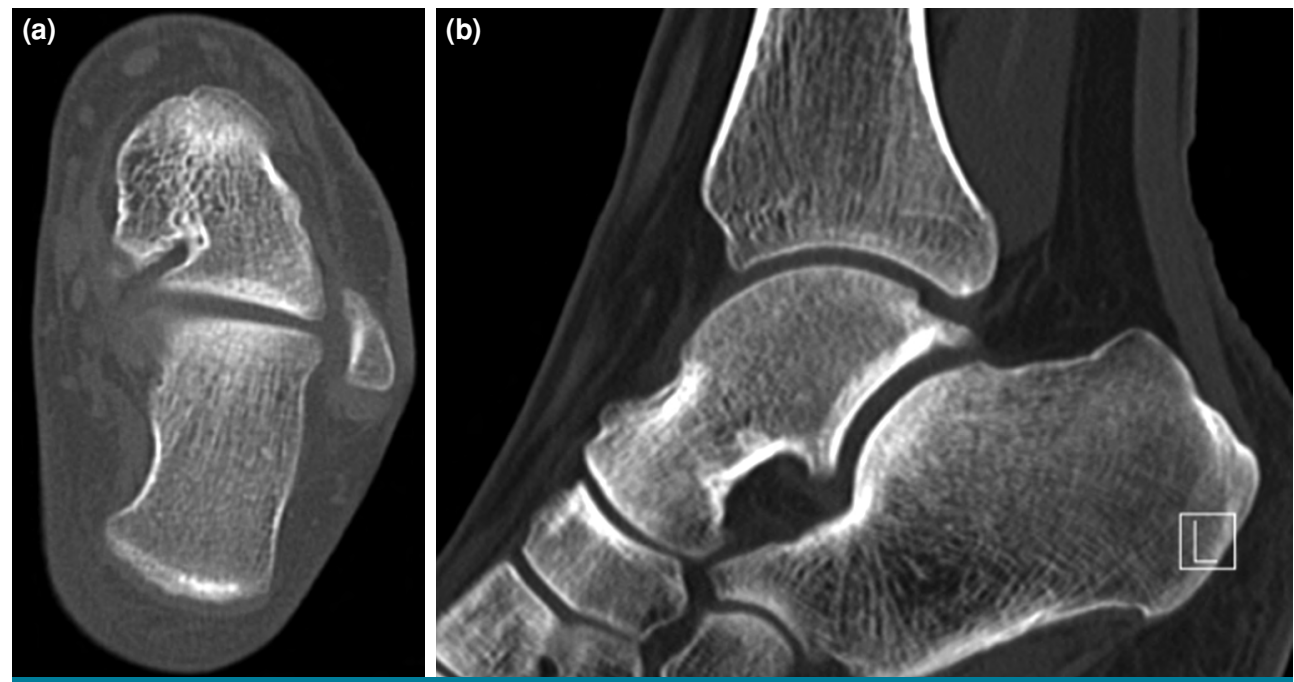

FIGURE 4. Postoperative axial and sagittal computed tomography images showing base after removal of lesion.

There was no recurrence of ankle pain at six months after treatment. Figure 4 shows postoperative sagittal and axial CT images of base after removal of the lesion.

\section{DISCUSSION}

The diagnosis of subperiosteal OO of the talar neck is usually delayed. Our patient also had ankle pain and synovitis findings that had not been diagnosed for two years. The delayed diagnosis was due to the fact that our patient had a history of trauma and the absence of any findings on radiography. There were arthrosynovitis findings confused with many diseases (chronic sprains, anterior impingement, stress fracture, osteomyelitis, osteonecrosis, monoarticular arthritis). In these cases, it is difficult to make a correct diagnosis because the early symptoms and radiological findings are both unclear in the early stages. It is important that $\mathrm{OO}$ be considered in the differential diagnosis of impingement syndrome, particularly in young people. The sensitivity of plain radiographs for diagnosing the intraarticular subperiosteal $\mathrm{OO}$ of the talar neck is reportedly as low as $61.5 \%{ }^{[6]}$ However, even if X-ray images are normal, closer evaluation may show sclerotic lesions in the talar neck. ${ }^{[9]}$

The MRI demonstrated the existence of bony edema and reactional changes in the soft tissue around the sclerotic lesion. ${ }^{[10]}$ Computed tomography has higher sensitivity than MRI, typically demonstrating a low- 
attenuation nidus with focal central calcification and surrounding sclerosis which could not be shown clearly in MRI. ${ }^{[6,7,10,11]}$ Therefore, in young patients with long-standing ankle pain, in case of misdiagnosed synovitis, effusion and bone marrow edema with MRI, OO may be considered in differential diagnosis and CT should be taken. Computed tomography is important for the diagnosis of early-stage lesions. ${ }^{[9]}$ Bone scintigraphy is highly sensitive to the diagnosis of OO. The double-ring appearance on scintigraphy is characteristic for OO. Because of synovial growth and hyperemia, intraarticular pathology may not show this characteristic finding. ${ }^{[12]}$

It is thought that the natural course of $\mathrm{OO}$ spontaneously heals in 2 to 15 years and the use of NSAIDs is recommended for less than two to three years. ${ }^{[13]}$ Conservative treatment should be considered if it is difficult to exclude the $\mathrm{OO}$ or if the patients refuse surgical treatment. ${ }^{[4]}$ However, NSAIDs are ineffective in one-third of patients for whom surgical intervention is required. ${ }^{[13]}$

Several methods such as open curettage, en bloc resection, CT-guided percutaneous ablation, and arthroscopic resection are used in the treatment of OO. ${ }^{[4]}$ These methods have advantages and disadvantages. Historically, these lesions were removed by open surgery. In recent years, arthroscopy in these cases is a seldom described treatment alternative. ${ }^{[6]}$ When nidus is located inside the bone, it cannot be detected by simple arthroscopic imaging and therefore the reference point should be determined based on preoperative $\mathrm{CT}$ to target the localization of the nidus. ${ }^{[14]}$ It has been shown that arthroscopic excision in intraarticular $\mathrm{OO}$ provides better results and less recurrence rate than other minimally invasive treatment options. ${ }^{[15-17]}$ Hetsroni et al., ${ }^{[14]}$ David et al., ${ }^{[17]}$ and Banerjee et al. ${ }^{[18]}$ described that complete exploration of the joint is possible with arthroscopy and the postoperative period is simplified with a reduced risk of infection and secondary stiffness as well as a lack of pain which occurs in open surgery. Another advantage of arthroscopic treatment is performing synovectomy during the arthroscopy. Also, it is easier to locate and completely visualize the tumor with arthroscopic surgery of subperiosteal OO of ankle joint. The surgeon's experience and skill are important factors in the success of arthroscopic surgery. In our case, we could not detect recurrence of the lesion in the CT scans performed after one year.

In the light of this information, arthroscopic removal of subperiosteal $\mathrm{OO}$ in the talar neck is a successful treatment method with low recurrence rate and high patient comfort. In addition, arthroscopic surgery has the advantages of having less soft tissue damage, less scar tissue, less postoperative pain, and early return to activity of daily living.

\section{Declaration of conflicting interests}

The authors declared no conflicts of interest with respect to the authorship and/or publication of this article.

\section{Funding}

The authors received no financial support for the research and/or authorship of this article.

\section{REFERENCES}

1. Tanrıverdi B, Erbahçeci Salık A, Çetingök H, Edipoğlu E, Bilgili MG, Güven K, et al. Multidisciplinary approach in the treatment of osteoid osteoma with radiofrequency ablation. Jt Dis Relat Surg 2020;31:255-9.

2. Capanna R, Van Horn JR, Ayala A, Picci P, Bettelli G. Osteoid osteoma and osteoblastoma of the talus. A report of 40 cases. Skeletal Radiol 1986;15:360-4.

3. Bauer TW, Zehr RJ, Belhobek GH, Marks KE. Juxtaarticular osteoid osteoma. Am J Surg Pathol 1991;15:381-7.

4. Ikegami M, Matsumoto T, Chang SH, Kobayashi H, Shinoda Y, Tanaka S. Anterior impingement syndrome of the ankle caused by osteoid osteoma in the talar neck treated with arthroscopy and 3D C-arm-based imaging. Case Rep Orthop 2017;2017:2171627.

5. Snow SW, Sobel M, DiCarlo EF, Thompson FM, Deland JT. Chronic ankle pain caused by osteoid osteoma of the neck of the talus. Foot Ankle Int 1997;18:98-101.

6. Jordan RW, Koç T, Chapman AW, Taylor HP. Osteoid osteoma of the foot and ankle--A systematic review. Foot Ankle Surg 2015;21:228-34.

7. Dubuc JE, Docquier PL, Schubert T, Galant C, Malghem J. Diagnosis failure led to the recurrence of an intra-articular osteoid osteoma at the talus neck after arthroscopic excision. Foot Ankle Surg 2014;20:e40-2.

8. Atik OŞ. Is there something new and interesting in my article? Eklem Hastalik Cerrahisi 2019;30:69.

9. $\mathrm{HeH}, \mathrm{Xu} \mathrm{H}, \mathrm{Lu} \mathrm{H}$, Dang Y, Huang W, Zhang Q. A misdiagnosed case of osteoid osteoma of the talus: a case report and literature review. BMC Musculoskelet Disord 2017;18:35.

10. Haller J, Bernt R, Seeger T, Weissenbäck A, Tüchler H, Resnick D. MR-imaging of anterior tibiotalar impingement syndrome: agreement, sensitivity and specificity of MR-imaging and indirect MR-arthrography. Eur J Radiol 2006;58:450-60.

11. Shukla S, Clarke AW, Saifuddin A. Imaging features of foot osteoid osteoma. Skeletal Radiol 2010;39:683-9.

12. Franceschi F, Marinozzi A, Papalia R, Longo UG, Gualdi G, Denaro E. Intra- and juxta-articular osteoid osteoma: a diagnostic challenge: misdiagnosis and successful treatment: a report of four cases. Arch Orthop Trauma Surg 2006;126:660-7.

13. Goto T, Shinoda Y, Okuma T, Ogura K, Tsuda Y, Yamakawa $\mathrm{K}$, et al. Administration of nonsteroidal anti-inflammatory drugs accelerates spontaneous healing of osteoid osteoma. Arch Orthop Trauma Surg 2011;131:619-25.

14. Hetsroni I, Nyska M, Edelshtein E, Mann G, Palmanovich E. Arthroscopic Excision of Osteoid Osteoma of the Talus. Arthrosc Tech 2017;6:e839-e43. 
15. Dimnjaković D, Bojanić I, Smoljanović T, Mahnik A. Periarticular osteoid osteoma of the ankle: a report of nine arthroscopically treated patients. J Foot Ankle Surg 2015;54:89-93.

16. Resnick RB, Jarolem KL, Sheskier SC, Desai P, Cisa J. Arthroscopic removal of an osteoid osteoma of the talus: a case report. Foot Ankle Int 1995;16:212-5.
17. David P, Legname M, Dupond M. Arthroscopic removal of an osteoid osteoma of the talar neck. Orthop Traumatol Surg Res 2009;95:454-7.

18. Banerjee D, Eriksson K, Morris H. Arthroscopically treated intraarticular osteoid osteoma in the ankle--a report of 3 cases. Acta Orthop 2005;76:721-4. 